\title{
Fitness characteristics of the malaria vector Anopheles funestus during an attempted laboratory colonization
}

\author{
Halfan S. Ngowo ${ }^{1,2^{*}}$ (1) , Emmanuel E. Hape ${ }^{1,2}$, Jason Matthiopoulos ${ }^{2}$, Heather M. Ferguson ${ }^{1,2+}$ \\ and Fredros O. Okumu $1,2,3,4+$
}

\begin{abstract}
Background: The malaria vector Anopheles funestus is increasingly recognized as a dominant vector of residual transmission in many African settings. Efforts to better understand its biology and control are significantly impeded by the difficulties of colonizing it under laboratory conditions. To identify key bottlenecks in colonization, this study compared the development and fitness characteristics of wild An. funestus from Tanzania (FUTAZ) and their $F_{1}$ offspring during colonization attempts. The demography and reproductive success of wild FUTAZ offspring were compared to that of individuals from one of the only An. funestus strains that has been successfully colonized (FUMOZ, from Mozambique) under similar laboratory conditions.
\end{abstract}

Methods: Wild An. funestus (FUTAZ) were collected from three Tanzanian villages and maintained inside an insectary at $70-85 \% \mathrm{RH}, 25-27^{\circ} \mathrm{C}$ and $12 \mathrm{~h}: 12 \mathrm{~h}$ photoperiod. Eggs from these females were used to establish three replicate $F_{1}$ laboratory generations. Larval development, survival, fecundity, mating success, percentage pupation and wing length were measured in the $F_{1}$-FUTAZ offspring and compared with wild FUTAZ and FUMOZ mosquitoes.

Results: Wild FUTAZ laid fewer eggs $(64.1 ; 95 \% \mathrm{Cl}[63.2,65.0])$ than FUMOZ females $(76.1 ; 95 \% \mathrm{Cl}[73.3,79.1])$. Survival of $F_{1}$-FUTAZ larvae under laboratory conditions was low, with an egg-to-pupae conversion rate of only $5.9 \%$ compared to $27.4 \%$ in FUMOZ. The median lifespan of $F_{1}$-FUTAZ females ( 32 days) and males ( 33 days) was lower than FUMOZ (52 and 49 for females and males respectively). The proportion of female $F_{1}$-FUTAZ inseminated under laboratory conditions (9\%) was considerably lower than either FUMOZ (72\%) or wild-caught FUTAZ females (92\%). This resulted in nearly zero viable $F_{2}$-FUTAZ eggs produced. Wild FUTAZ wings appear to be larger compared to the lab reared $F_{1}-$ FUTAZ and FUMOZ.

Conclusions: This study indicates that poor larval survival, mating success, low fecundity and shorter survival under laboratory conditions all contribute to difficulties in colonizing of An. funestus. Future studies should focus on enhancing these aspects of An. funestus fitness in the laboratory, with the biggest barrier likely to be poor mating.

*Correspondence: hngowo@ihi.or.tz

${ }^{\dagger}$ Heather M. Ferguson and Fredros O. Okumu contributed equally to the work

${ }^{1}$ Department of Environmental Health and Ecological Sciences, Ifakara Health Institute, P.O. Box 53, Ifakara, Tanzania

Full list of author information is available at the end of the article

\begin{abstract}
Background
Malaria transmission in Africa is dominated by species in the Anopheles gambiae and Anopheles funestus species complexes. Control of these vectors has been the primary driver of malaria reduction since 2000 [1, 2], and requires thorough understanding of their ecology, behaviours and transmission potential [3-9]. Laboratory colonies of $A n$. gambiae sensu lato (s.l.) have been an invaluable resource
\end{abstract}

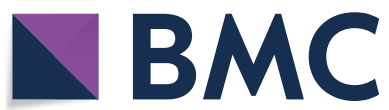

(c) The Author(s) 2021. This article is licensed under a Creative Commons Attribution 4.0 International License, which permits use, sharing, adaptation, distribution and reproduction in any medium or format, as long as you give appropriate credit to the original author(s) and the source, provide a link to the Creative Commons licence, and indicate if changes were made. The images or other third party material in this article are included in the article's Creative Commons licence, unless indicated otherwise in a credit line to the material. If material is not included in the article's Creative Commons licence and your intended use is not permitted by statutory regulation or exceeds the permitted use, you will need to obtain permission directly from the copyright holder. To view a copy of this licence, visit http://creativeco mmons.org/licenses/by/4.0/. The Creative Commons Public Domain Dedication waiver (http://creativecommons.org/publicdomain/ zero/1.0/) applies to the data made available in this article, unless otherwise stated in a credit line to the data. 
for research by enabling experimental studies under controlled conditions. Such colonies have facilitated the characterization of insecticide resistance [10-12], genetics $[13,14])$, immunity $[15,16]$ and key vector demographic profiles [17-19]. Mosquitoes generated from laboratory colonies are also extensively used for semifield bioassays $[4,20,21]$.

In contrast to An. gambiae s.l., An. funestus s.l. has proven extremely difficult to colonize and maintain under laboratory conditions. The An. funestus species complex group consists of at least 13 known species: Anopheles aruni, Anopheles brucei, Anopheles confusus, Anopheles funestus sensu stricto (s.s.), Anopheles funestus-like, Anopheles fuscivenosus, Anopheles leesoni, Anopheles longipalpis type A, Anopheles longipalpis type C, Anopheles parensis, Anopheles rivulorum, Anopheles rivulorum-like and Anopheles vaneedeni [22-25]. These species vary in vectorial capacity [26], with only An. funestus s.s. thought to play a significant role in malaria transmission [27, 28]. Others, such as An. rivulorum, have been reported as minor vectors in Kenya [29], Tanzania [30] and $A n$. vaneedeni in South Africa [31].

Colonization of An. funestus s.s. has however been problematic, and only two strains have been successfully colonized from wild populations despite several attempts. Both strains were colonized at the Vector Control Reference Laboratory (VCRL) in the National Institute for Communicable Diseases, South Africa, from populations in Angola (FANG) and Mozambique (FUMOZ) [32, 33]. The FUMOZ strain also maintained at other laboratories worldwide, including in Cameroon and in the UK [12], as well as in Tanzania. Several attempts have been made to colonize new An. funestus strains [34] from wild populations, but methods used to establish FUMOZ and FANG have not been successful elsewhere [35], including when attempted in the same wild populations where FUMOZ was originally derived (Coetzee, pers. commun.). This inability to repeatedly colonize and establish An. funestus in laboratories is responsible for the more limited understanding of the biology of this species compared to other vector species.

Several factors may account for the difficulty of colonizing An. funestus. Chief amongst these is eurygamy, the inability of an insect to mate in flight [36, 37]. Eurygamic species are difficult to colonize because they do not exhibit natural mating behaviours, such as swarming [38], under insectary conditions [36, 39, 40]. Many Anopheles mosquitoes mate naturally in aerial swarms [41-43] or, to a smaller extent, indoors [44]. Whilst $A n$. gambiae will mate readily in the laboratory [4], wild and $\mathrm{F}_{1}$ progeny of $A n$. funestus rarely swarm inside cages. Although mating is hypothesized to be the main barrier to An. funestus colonization, other factors cannot be ruled out due to incomplete or absence of reporting on other aspects of their life history and fitness during attempted colonization. Therefore, it is crucial to comprehensively evaluate how all aspects of An. funestus life history, development and demography respond to standard methodologies for colonization in order to identify where modifications should be focused.

Malaria eradication in most African settings will require a more detailed understanding of the basic biology and ecology of vectors of residual transmission, and which additional strategies will most effectively target them. Historically, most research on African malaria vectors has also been concentrated on the Anopheles gambiae s.l. species group. Anopheles funestus has also recognized as an important vector in many African settings [26, 27, 45]; and is now the dominant source of transmission in many areas following the decline of An. gambiae [27, 28, 46]. However in contrast to $A n$. gambiae s.l., much less is known about the ecology and fundamental biology of An. funestus s.l. This knowledge gap is due to a range of factors including the more cryptic nature of it larval habitats and most notably the difficulties with colonizing it. Given the growing prominence of this species in mediating residual transmission across Africa, there is a clear need to overcome these obstacles as required to guide the development and implementation of more effective control strategies.

To address these knowledge gaps, the fitness and behavior of wild An. funestus from Tanzania and their offspring (defined as "FUTAZ", i.e. An. funestus from Tanzania), were quantified during repeated colonization attempts under standard laboratory conditions. From previous studies, it is known that colonization of this species using standard approaches is difficult. The first step in optimizing this process is to understand which aspects of An. funestus life-history and fitness are most impaired during colonization, and thus target modifications appropriately. To assess this, a detailed measurement of the fitness and life-history of wild and $\mathrm{F}_{1}$ An. funestus were conducted during repeated laboratory colonization attempts. Fitness measures of individuals in this nascent colony were compared to those of a stable An. funestus colony (FUMOZ) to identify the key barriers that hinder successful colonization of this species. The term "fitness trait" refers to measures of mating success (insemination status), fecundity (number of eggs produced), adult body size and survival (larval and adult). Insights gained will guide future research to overcome barriers to colonizing An. funestus, and also increase knowledge on this important vector and its control. 


\section{Methods}

\section{Study area}

Wild An. funestus s.l adults were collected from three villages (Tulizamoyo, Ikwambi and Sululu) in Kilombero $\left(8.1539^{\circ} \mathrm{S}, 36.6870^{\circ} \mathrm{E}\right)$ and Ulanga $\left(8.3124^{\circ} \mathrm{S}, 36.6879^{\circ} \mathrm{E}\right)$ districts in Tanzania (Fig. 1). The villages were selected because of their high abundance of An. funestus s.l., of which $>93 \%$ are known to be An. funestus s.s. [47]. Wildcaught females were transported to the Ifakara Health Institute and used in experiments at the vector biology \& control laboratory, the VectorSphere at Ifakara (Fig. 1).

\section{Mosquito sampling}

Five houses were selected for mosquito collection in each village. Mosquito collections were conducted for one week in each village in 2019 (Tulizamoyo: 17-23rd June; Ikwambi: 8-16th July and Sululu: 1-10th September). Due to collection logistics and space limitation in the VectorSphere, only one set of experiments (i.e. with mosquitoes from just one village) was done at a time. Trapping was done using CDC light traps $[48,49]$ that were set from $6 \mathrm{pm}$ to 6 am for five consecutive nights per village (yielding 200-300 female An. funestus s.l. per week). Light traps were fitted with larger catch bags to help keep mosquitoes alive without desiccation until morning. Every morning, live female An. funestus s.l. were aspirated from the catch bags into netted cages $(30 \times 30 \mathrm{~cm})$, provided with $10 \%$ glucose solution and brought to the VectorSphere for blood-feeding and further rearing. Inside the VectorSphere mosquitoes were kept under standard conditions of $70-85 \% \mathrm{RH}, 25-27{ }^{\circ} \mathrm{C}$ and a $12 \mathrm{~h}: 12 \mathrm{~h}$ photoperiod.

\section{Laboratory maintenance and fitness measurements for FUTAZ mosquitoes}

Once in the VectorSphere, wild female of $A n$. funestus s.l. were given an initial blood meal from a chicken for a maximum of $30 \mathrm{~min}$ (from 6:30 pm) inside cages covered with dark cloth. After this first blood meal, mosquitoes were left in the cage until the next morning when their feeding success was recorded by visual observation. Those with a distended, red abdomen

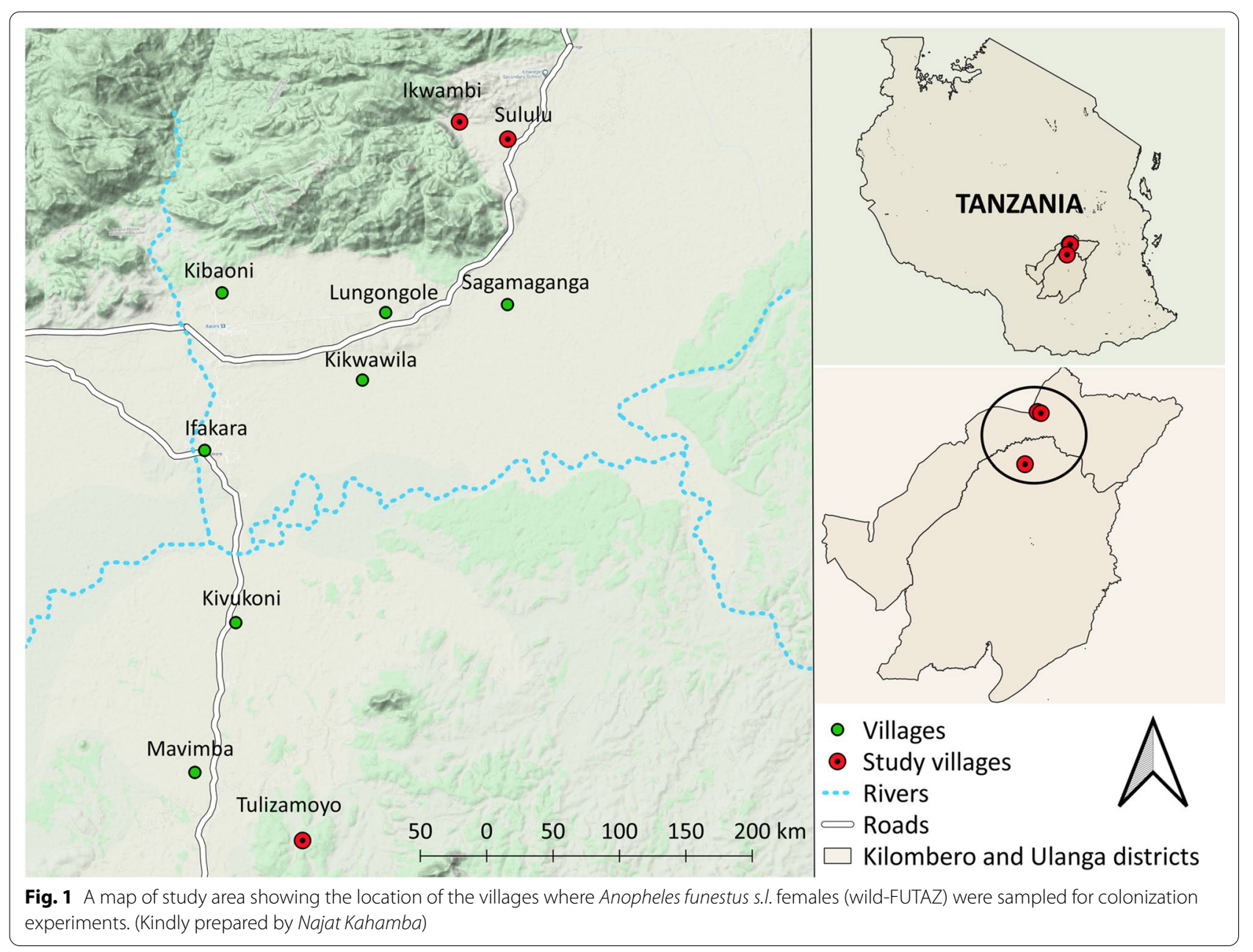


were considered to be fully engorged and transferred into individual oviposition cups for egg laying (Additional file 1: Fig. S1). Cotton pads soaked in 10\% glucose solution were placed onto the top netting over the cups for additional nutrition. After three days, a small amount of water $(\sim 5 \mathrm{ml})$ was put in each cup to stimulate oviposition. Cups were then inspected daily to record if and when eggs were laid, and dead mosquitoes were removed. Mosquitoes that did not lay eggs after 12 days were killed by freezing for $10 \mathrm{~min}$ and later dissected to assess insemination. The terminalia and last abdominal segment (segment IX) were cut-open in distilled water to expose the spermathecae. Slide mounts of spermathecae were inspected using a microscope at $400 \times$ magnification for presence of sperm (Fig. 2a\&b).

$\mathrm{F}_{1}$ eggs from wild-caught An. funestus s.l. were identified to species-level based on their morphological characteristics [50]. Eggs were observed under a Stereo Microscope, and sub-samples of emergent adults verified by PCR [51]. All eggs morphologically confirmed as belonging to $A n$. funestus s.s., were retained for use in subsequent colonization and life history experiments and defined as $F_{1}$-FUTAZ (Fig. 2c). Here, all $F_{1}$-FUTAZ eggs were pooled and redistributed into a series of $5 \mathrm{~L}$ round plastic basins $(30 \mathrm{~cm}$ diameter, filled to $3.3 \mathrm{~cm}$ with tap water, replaced every 2 days) at approximate densities of 400-600 eggs per basin and left to hatch. There were a

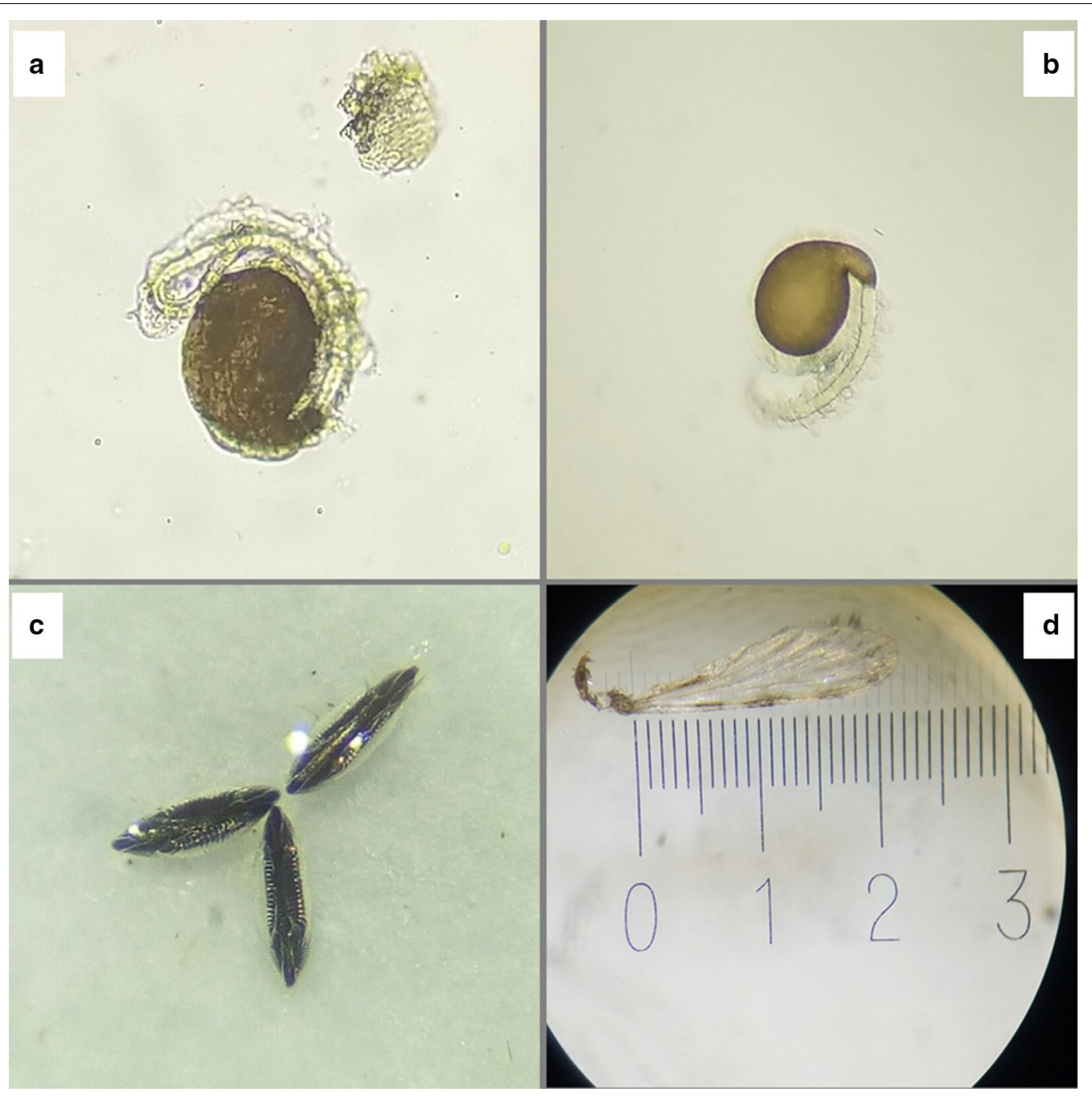

Fig. 2 Microscopic images of spermathecae showing the (a) presence of the spermatozoa as the confirmation for insemination and (b) absence of spermatozoa suggesting non-inseminated, (c) Egg structure of the female Anopheles funestus s.s. as seen under microscope, a quick and cheap method of species distinction within Anopheles funestus group during colonization instead of standard Polymerase Chain Reaction (PCR) and (d) the wing measurement under microscope showing the apical notch and the auxiliary margin 
total of 12 replicate basins set up for each of the 3 independent colonization experiments (1 per study village). From here onwards, the term An. funestus refers specifically to An. funestus s.s.

Larvae were fed daily with a pinch (approx. $0.36 \mathrm{~g}$ ) of a mixture of finely crushed dog biscuits and brewer's yeast at a ratio of 3:1 [32]. Basins were checked daily to record egg hatching and larval survival. Pupae that emerged over three consecutive days were recorded and retained for use in $F_{1}$ adult mosquito fitness experiments. Female: male ratio was also recorded at this stage by looking at the genital lobe shape (i.e. at the end of the pupae abdominal segments just below the paddles, also males tends to be smaller than females [52, 53]. Pupae were placed in a single cage $(30 \times 30 \mathrm{~cm})$ and monitored until emergence (1-2 days). A total of three cages were set up for each of the three independent colonization experiments.

$\mathrm{F}_{1}$ FUTAZ females were offered their first human blood meal five days post-emergence, on the same day and time as females from the FUMOZ colony their fitness was compared with (see below). Females were provided with additional blood meals every five days. The rationale for blood feeding every 5 days was to estimate the survival under conditions where they had access to blood meals at a frequency similar to that expected in the wild. Studies indicate that the gonotrophic cycle length of An. funestus ranges between 2 and 5 days [54, 55]; with 5 being selected here due to practical considerations. From the first blood meal onwards, cages were inspected daily to record and remove all dead mosquitoes. A total of three cages were used as replicates in each of the 3 independent colonization experiments. All the dead females were dissected to assess insemination status. Random subsamples of $F_{1}$ females were selected after the second blood meal and moved into individual oviposition cups to measure their egg production.

\section{Laboratory maintenance and fitness measurements for FUMOZ mosquitoes}

In July 2018, eggs from the FUMOZ An. funestus colony were obtained from the VCRL laboratory in South Africa and used to establish a colony within the VectorSphere, at Ifakara Health Institute in Tanzania. The founder FUMOZ colony at VCRL has been maintained since 2000 [32]. At IHI, the FUMOZ colony was maintained for four generations before starting these experiments. This colony was kept under the same insectary conditions (70-85\% RH, $25-27{ }^{\circ} \mathrm{C}$ and $12 \mathrm{~h}: 12 \mathrm{~h}$ photoperiod) in the VectorSphere and same feeding regime as described above for $\mathrm{F}_{1}$-FUTAZ. In this study, the following fitness variables were measured in FUMOZ for comparison with FUTAZ: number of eggs laid per mosquito (fecundity), proportion of eggs hatched, wing lengths, proportion of adult female inseminated, proportion of larvae survived, larval development period, and proportion of pupae emerged as adult, female: male sex ratio at pupae stage and number of days survived by adult females. The definition of all fitness traits measured, and the colonies in which they were made were given in (Additional file 1: Table S1).

\section{Mosquito wing size measurements}

The wing lengths of all female An. funestus (Wild FUTAZ, $F_{1}$-FUTAZ and FUMOZ) were measured and used as a proxy for their body size. One wing was removed from each mosquito and placed onto a drop of water on a microscope slide. The wing lengths were measured using the micrometer ruler under a microscope $(50 \mathrm{~mm}$ micrometer scale in $0.1 \mathrm{~mm}$ divisions, $70 \mathrm{~mm} \times 20 \mathrm{~mm} \times 3 \mathrm{~mm}$ ) [56]. Measurements were taken from the apical notch to the auxiliary margin, excluding the wing fringe (Fig. 2d).

\section{Ethics}

This study was approved by Ifakara Health Institute Institutional Review Board (Ref. IHI/IRB/No: 007-2018) and the Medical Research Coordinating Committee (MRCC) at the National Institute for Medical Research-NIMR (Ref: NIMR/HQ/R.8a/Vol.IX/2895). Permission to publish was obtained from NIMR (Ref: NIMR/HQ/P.12 VOL $\mathrm{XXXI} / 57)$. Individual verbal and written consent was also obtained from household owners where CDC light traps were placed for collecting mosquitoes and verbal consent for the arm-feeders in the insectary.

\section{Statistical analysis}

Data analyses were conducted using $\mathrm{R}$ statistical software version 3.5.0 [57]. Mean values were estimated for An. funestus fitness traits (Additional file 1: Table S1 in SI), and how these variables differs between FUTAZ and FUMOZ strains. Where possible, fitness traits (i.e. wing length and proportion inseminated) were also compared among the wild FUTAZ, $\mathrm{F}_{1}$-FUTAZ and FUMOZ. Additional analysis was conducted to assess the relationship between female body size and fecundity (number of eggs produced) in wild FUTAZ and FUMOZ.

Generalized linear mixed models (GLMM) implemented in lme4 package [58] were used to estimate mean values of fitness traits in wild and $F_{1}$-FUTAZ and FUMOZ strains. Fecundity, the number of eggs laid per mosquito, was modeled as a Poisson variate and wing length was included in the model as fixed effects. For proportion data (here, emergence, insemination, larval survival and sex ratio, (Additional file 1: Table S1) were modeled as a binomial variate with strain used as fixed effects while replicates as random effects. Wing 
length and strain were also used as fixed effect when assessing insemination. Wing length was modeled as a Gamma variate with an inverse link function, incorporating strain as fixed effect. Tukey's post-hoc tests were used to assess the means differences for different fitness measurements.

Survival analyses were done using a Cox proportional hazard model using the survival package [59] to assess the odds of mortality for males and females for each strain and for females of the two strains of An. funestus ( $\mathrm{F}_{1}$-FUTAZ vs. FUMOZ). Here, the response variable was the death occurring on each day of observation, while strains and sex were included as explanatory variables. In the analysis of $F_{1}$-FUTAZ, site of collection was included as a random effect by fitting a frailty function $[60,61]$ using a Gamma distribution. Separate analyses were performed for each strain except when the differences between strains were investigated. Log likelihood ratio tests (LRT) were used to test the significance of each variable of interest in all models. All figures were produced using ggplot2 [62] and survminer [63] R packages.

\section{Results}

A total of 1,130 adult females of the wild-FUTAZ strain were collected from the three different villages, Tulizamoyo $(\mathrm{n}=332)$; Ikwambi $(\mathrm{n}=425)$; Sululu $(\mathrm{n}=373)$. More than two-thirds $(n=804)$ of these successfully fed when offered a blood-meal in the insectary, of which $39 \%$ $(\mathrm{n}=316)$ laid eggs in the insectary.

\section{Mosquito wing lengths, mating status, fecundity and pupation}

Anopheles funestus wing lengths varied significantly between groups $\left(\chi^{2}=14.97, \mathrm{p}<0.001\right.$, Fig. 3a). A Tukey's post-hoc test showed that the wild-collected FUTAZ were larger than lab reared $\mathrm{F}_{1}$-FUTAZ $(\mathrm{z}=3.23, \mathrm{p}<0.01$, Fig. 3a) and FUMOZ $(z=2.52, p<0.05$, Fig. 3a). There was no difference in wing lengths between the two laboratory-reared strains, FUMOZ and $\mathrm{F}_{1}$-FUTAZ $(\mathrm{z}=1.43$, $p=0.303$, Fig. 3a). The wing lengths of $F_{1}$-FUTAZ $\left(x^{2}=10.4, \quad \mathrm{p}<0.01\right)$ but not FUMOZ $\left(x^{2}=0.123\right.$, $\mathrm{p}=0.688)$ were positively associated with insemination status. Furthermore, the proportion inseminated varied significantly between strains $\left(\chi^{2}=177.2, \mathrm{p}<0.001\right.$,

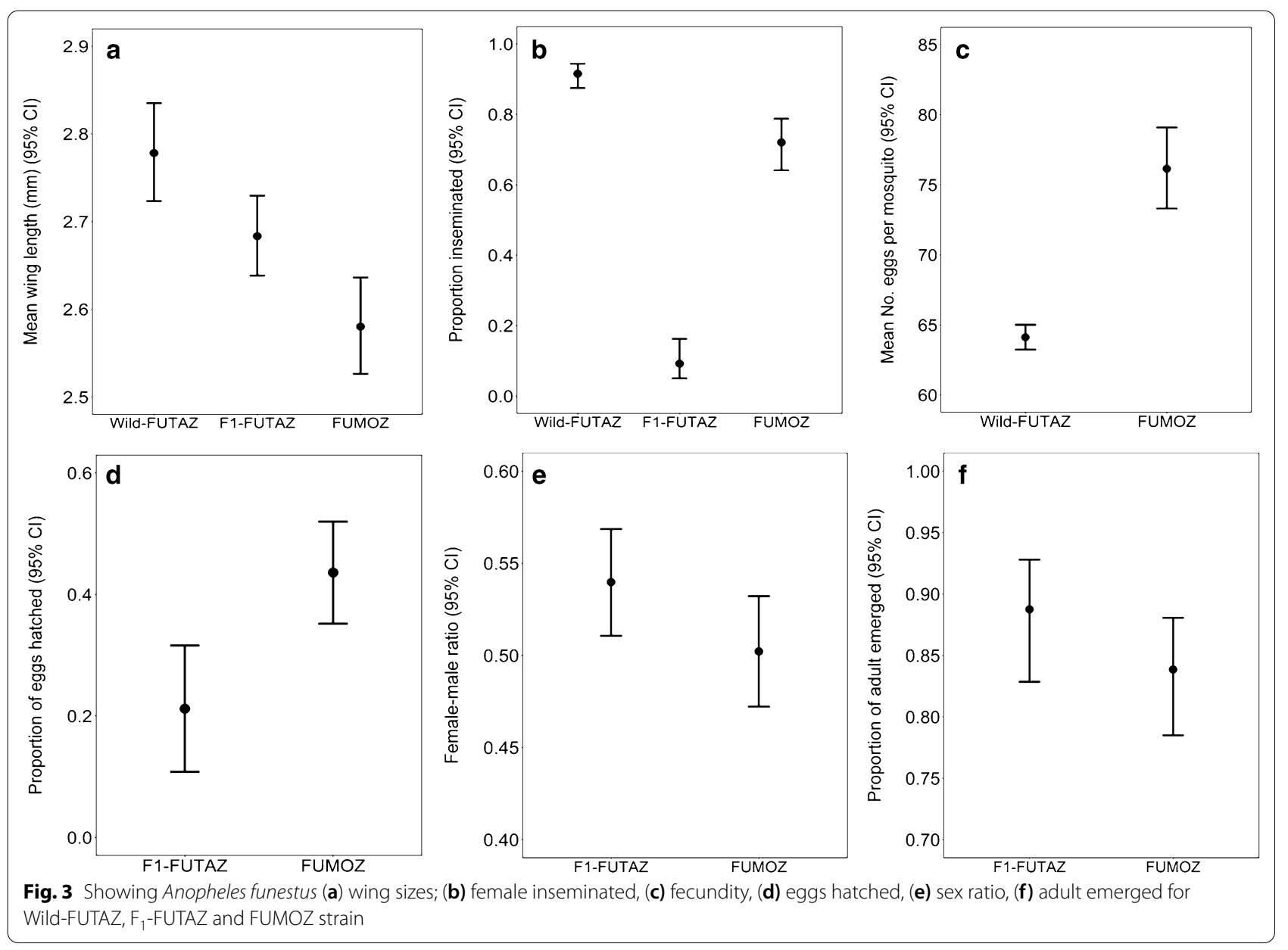



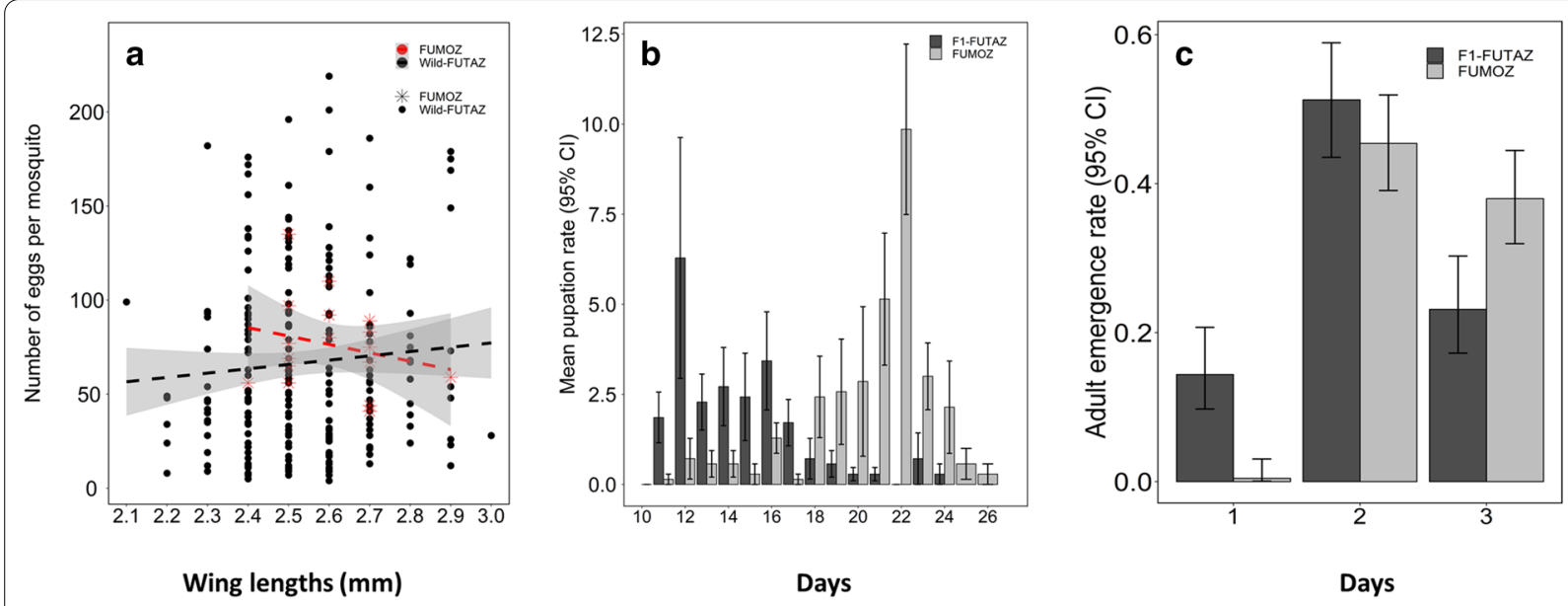

Fig. 4 Anopheles funestus (a) relationship between mosquito body sizes and number of eggs produced per Anopheles funestus mosquito, (b) larvae period and (c) Pupae period

Fig. 3b), and the two generations of FUTAZ $\left(\chi^{2}=172.3\right.$, $\mathrm{p}<0.001$, Fig. $3 \mathrm{~b})$. Insemination was considerably lower in $\mathrm{F}_{1}$-FUTAZ (9\%) compared to wild caught FUTAZ females (92\%) and FUMOZ (72\%; Fig. 3b).

Fecundity varied between strains $\left(\chi^{2}=66.54, \mathrm{p}<0.001\right)$ with FUMOZ females producing significantly more eggs than wild-FUTAZ (Fig. 3c, Table 1). FUMOZ clutch size ranged from 41-137 eggs while wild-FUTAZ clutch sizes range from 3-236 eggs. The proportion of eggs hatched into $1^{\text {st }}$ instar larvae was $21 \%$ [95\% CI; 10.8, 31.6] in $\mathrm{F}_{1}$-FUTAZ and 44\% [35.2, 52.0] in FUMOZ (Fig. 3d). No eggs were produced by $\mathrm{F}_{1}$-FUTAZ. The impact of wing length on fecundity varied between strains $\left(\chi^{2}=62.57\right.$, p $<0.001$, Fig. 4a).

The median larval development period from $1^{\text {st }}$ instar larvae to pupation was 22, IQR: 21-23 days in FUMOZ, and only 13, IQR: 11-14 days in $\mathrm{F}_{1}$-FUTAZ (Fig. 4b). Overall, the proportion of eggs surviving to pupation was $5.87 \%$ in $\mathrm{F}_{1}$-FUTAZ and $27.4 \%$ in FUMOZ, reflecting significant variation between strains $\left(\chi^{2}=11.28, \mathrm{p}<0.001\right.$, Table 2). The sex ratio (females: males) in pupae varied marginally between strains $\left(\chi^{2}=3.89, p=0.049\right.$, Fig. 3e), with a slightly higher proportion of females in $F_{1}$-FUTAZ compared to FUMOZ (Table 2). The proportion of adults that emerged from pupae was similar in $F_{1}$-FUTAZ and FUMOZ $\left(\chi^{2}=1.91, p=0.167\right.$, Fig. 3f), with most adults emerging on the second day of pupation (Fig. 4c).

\section{Adult survival}

The median survival of adult female $F_{1}$-FUTAZ was 32 (IQR: 26, 40) and 33 days (IQR: 27, 41) for males (Fig. 5a). In FUMOZ, the median survival for females was 52 days (IQR: 39,56$)$ and 49 days (IQR: 42,56$)$ for males
Table 1 Relative odds (OR) and means of insemination, sex ratio, pupation and adult emergence for different strains of Anopheles funestus, number in brackets are 95\% confidence intervals with their respective $p$-values

\begin{tabular}{|c|c|c|c|c|}
\hline Variable & Strain & Mean \pm 2 SE & OR [95\% Cl] & P-value \\
\hline \multirow[t]{3}{*}{ \%Insemination } & Wild-FUTAZ & $91.5 \pm 1.30$ & 1 & \\
\hline & $F_{1}$-FUTAZ & $9.2 \pm 4.99$ & $\begin{array}{l}0.009[0.004 \\
0.020]\end{array}$ & $<0.001$ \\
\hline & FUMOZ & $72.0 \pm 5.16$ & $0.24[0.13,0.42]$ & $<0.001$ \\
\hline \multirow[t]{2}{*}{ \%Sex ratio (F/M) } & $F_{1}$-FUTAZ & $53 \pm 4.0$ & 1 & \multirow[t]{2}{*}{$=0.049$} \\
\hline & FUMOZ & $50 \pm 2.9$ & $0.86[0.74,0.99]$ & \\
\hline \multirow[t]{2}{*}{ \%Larval survival } & $F_{1}$-FUTAZ & $5.3 \pm 3.5$ & 1 & \multirow[t]{2}{*}{$<0.001$} \\
\hline & FUMOZ & $27.4 \pm 12.5$ & $\begin{array}{c}12.05[4.27 \\
34.03]\end{array}$ & \\
\hline \multirow{2}{*}{$\begin{array}{l}\text { \%Adult emer- } \\
\text { gence }\end{array}$} & $\mathrm{F}_{1}$-FUTAZ & $88.8 \pm 7.35$ & 1 & \multirow[t]{2}{*}{$=0.174$} \\
\hline & FUMOZ & $81.6 \pm 8.90$ & $0.66[0.36,1.20]$ & \\
\hline
\end{tabular}

Table 2 Relative risk (RR) and means of fecundity for different strains of Anopheles funestus, number in brackets are 95\% confidence intervals

\begin{tabular}{lllll}
\hline Variable & Strain & Mean \pm 2 SE & RR $[95 \% \mathrm{Cl}]$ & P-value \\
\hline Fecundity & Wild-FUTAZ & $64.1 \pm 5.26$ & 1 & \\
& FUMOZ & $76.1 \pm 7.61$ & $0.84[0.81,0.88]$ & $<0.001$ \\
\hline
\end{tabular}

(Fig. 5b). There was no difference in the survival of males and females within either strain, $\mathrm{F}_{1}$-FUTAZ $(\mathrm{p}=0.468$, Table 3) and FUMOZ ( $\mathrm{p}=0.752$, Table 3$)$. However, restricting analysis to adult females, survival was significantly lower in $\mathrm{F}_{1}$-FUTAZ than FUMOZ $(\mathrm{p}<0.001$, 


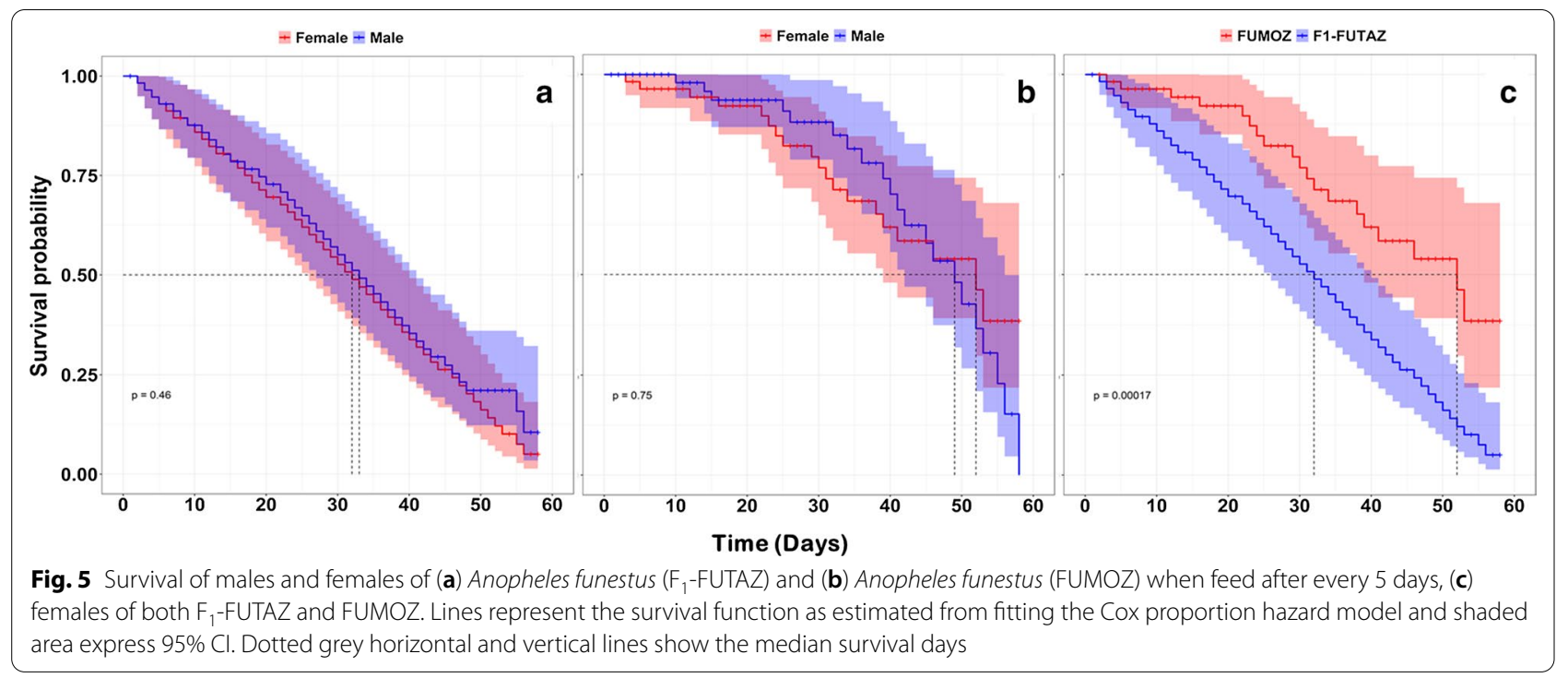

Table 3 Hazard Ratio and median values of the adult survival between males and females of the $F_{1}$-FUTAZ and FUMOZ, associated $p$-values indicate the significance difference of sex and species on the number of days survived by $F_{1}$-FUTAZ and FUMOZ strains

\begin{tabular}{lllll}
\hline Strain & Sex & Median $[\mathrm{IQR}]$ & HR $[95 \% \mathrm{Cl}]$ & P-value \\
\hline F $_{1}$-FUTAZ & Female & $32[26,40]$ & 1 & $=0.468$ \\
& Male & $33[27,41]$ & $0.89[0.65,1.24]$ & \\
FUMOZ & Female & $52[39,56]$ & 1 & $=0.752$ \\
& Male & $49[42,56]$ & $1.11[0.59,2.06]$ & \\
Female & FUMOZ & $52[39,56]$ & 1 & $<0.001$ \\
& F $_{1}$-FUTAZ & $32[26,40]$ & $2.63[1.55,4.46]$, & \\
Male & FUMOZ & $49[42,56]$ & 1 & $<0.01$ \\
& F $_{1}$-FUTAZ & $33[27,41]$ & $2.05[1.22,3.45]$ & \\
\hline
\end{tabular}

Table 3, Fig. 5c). Likewise, adult males survival was significantly lower in $F_{1}$-FUTAZ than FUMOZ $(\mathrm{p}<0.01$, Table 3).

\section{Discussion}

Limited understanding of mosquito biology and ecology poses a challenge for the development of effective vector control approaches. Laboratory colonization of target species provides an opportunity to address these knowledge gaps by facilitating detailed investigation of vector biology under controlled conditions where experimental manipulation is possible. Here the fitness traits of $A n$. funestus during colonization attempts from a wild population in Tanzania were characterized to identify the bottlenecks that make this species so difficult to colonize. This is the first documentation of fitness constraints during attempted colonization of this species and the first report of attempted colonization of An. funestus from Tanzania.

Consistent with most previous attempts, colonization of this wild An. funestus population proved unsuccessful with no offspring being produced from the $\mathrm{F}_{1}$ generation. Several life history processes and demographic traits were identified as being impaired when FUTAZ were brought into the laboratory. First, there number of eggs laid by wild FUTAZ when brought in the insectary was lower than in the well-establish FUMOZ line, as were hatching rates, larval survival, mating success and adult female/male survival. $F_{1}$ FUTAZ body sizes were slightly smaller compared to their maternal generation in the wild, but did not differ with the FUMOZ strain indicating this trait is unlikely to predict colonization success. Of all these fitness traits, the primary hurdles to colonization are likely to be the extremely low mating success and larval survival of $\mathrm{F}_{1}$ An. funestus in the laboratory. Until these fitness traits can be improved under laboratory conditions, the colonization of An. funestus is unlikely to be successful and repeatable.

Eggs laid by wild-FUTAZ An. funestus had low proportion of hatching compared to those of FUMOZ, though they were both lower than $50 \%$, indicating many were unviable eggs laid by non-inseminated females. Previous studies investigating the impact of different water sources used for larval rearing in an An. funestus colony (FUMOZ) indicated that their egg hatching rate can exceed 70\% [64, 65]; confirming hatch rates in this study were low. It is known that females of other Anopheles species can produce unviable eggs without successful mating, or after mating with sperm-less males [66]. 
Therefore, poor hatching observed in the nascent strain (FUTAZ) here is likely due to first, the low mating success of An. funestus in captivity as has been previously documented in other Anopheles species [35], second since the number of eggs laid was very low, the absence of any hatching could be just stochastic effect, lastly, low hatching rate could also be associated with suboptimal temperature in the laboratory relative to the one in the field to which FUMOZ strain might have been well adapted to it but not FUTAZ [67].

The larval development period of $\mathrm{F}_{1}$-FUTAZ (1114 days) was similar to that reported for An. funestus in other laboratory settings $[64,65,68]$, but faster than FUMOZ development period (21-23 days) observed in this study. The duration of larval development in $A n$. funestus (FUTAZ and FUMOZ) observed here were considerably longer than described for An. gambiae complex in the laboratory [69]. For example, life table analyses of An. gambiae indicate larval development period from eclosion to adult emergence of about 11 days at $27{ }^{\circ} \mathrm{C}$ [55, 69-72]. This long larval development period for $\mathrm{F}_{1}$-FUTAZ results in a long estimated generation time of 30-33 days from eggs to first oviposition; which is higher than estimated for other African Anopheles species [64, $73,74]$. Other life table analyses performed on An. funestus colonies estimated a generation time of approximately 33 days in insecticide-resistant (FUMOZ) and susceptible strains (FANG), [65]. As a consequence of this extended period of larval development, the egg to pupa survival was very low; approximately $6 \%$ for $\mathrm{F}_{1}$-FUTAZ and $27 \%$ for FUMOZ. Due to this long larval development and associated high larval mortality, very large numbers of eggs would be required generate modest numbers of adults in the laboratory. Therefore, the fitness and reproductive success of these resulting adults would have to be very high to yield a further generation.

Analysis of wild FUTAZ adults and their $\mathrm{F}_{1}$ offspring indicate their fitness is reduced compared to that of a stable An. funestus colony (FUMOZ). Wild-FUTAZ An. funestus brought into the laboratory laid $16 \%$ fewer eggs than the FUMOZ colony, and the $F_{1}$ generation of FUTAZ produced no viable eggs at all. A previous study measuring the fecundity of $\mathrm{F}_{1}$ An. funestus using Madagascan population reported that this species can lay and average of 56 to 108 eggs per mosquito in captivity [35], which corroborates with 65 and 76 eggs from wild-FUTAZ and FUMOZ, respectively, from the current study. The number of eggs here is consistent to that reported in resistant and susceptible An. funestus strains in the laboratory, [65].

Mosquito body size is often interpreted as a proxy of their fitness [75-77]. Here, wild FUTAZ were somewhat larger in body size than $\mathrm{F}_{1}$-FUTAZ and FUMOZ.
Consistent with the hypothesis of body size being an indicator of fitness, wing length was positively correlated with fecundity in the wild population of An. funestus (FUTAZ). However, the opposite was seen in the stable FUMOZ strain where wing size was negatively associated with fecundity. Thus, at least in this one stable laboratory colony, large body size in An. funestus was not a good indicator of reproductive success. Caution is required in extrapolating fitness differences based on An. funestus body size, particularly between field and laboratory strains. Although body size fell between wild-FUTAZ and $F_{1}$-FUTAZ, these mosquitoes were still bigger than the FUMOZ which had the highest fecundity.

The mating success of An. funestus from these populations was extremely low in the laboratory, supporting hypothesis that mating is the key bottleneck for the colonization of this species. Compared to wild-FUTAZ, insemination rates in $F_{1}$-FUTAZ were extremely low $(9.2 \%$ vs. $72 \%)$ and insufficient to establish a further generation $\mathrm{F}_{2}$-FUTAZ. This poor mating success is likely due eurygamy, the inability of some Anopheles species including An. funestus to initiate natural swarming behaviour in flight $[78,79]$. These findings match those of other studies documenting mating as the major obstacle for successful colonization of An. funestus [34, 35, 80]. To overcome this problem, techniques such as forced mating and exposing mosquitoes during sunset to induce swarming have been applied [81, 82]. Other studies have experimented with the use of large cages to stimulate natural mating for Anopheles, and simulate sunset which may be crucial cue for mating [83, 84]. However so far these methods have had little or no success over multiple attempts [32, 34]. In the current study, no $\mathrm{F}_{2}$-FUTAZ offspring were generated because none of the $F_{1}$-FUTAZ laid viable eggs. Further research on how to induce mating behavior in An. funestus, particularly using more realistic semi-field systems, would be of great value. Such studies must focus on both females and males, to determine if males are unwilling to initiate swarming behaviour or not fit enough to do so.

Analysis of adult mosquito survival indicated that the nascent Tanzania colony ( $\mathrm{F}_{1}$-FUTAZ) had a reduced lifespan compared to stable An. funestus colony (FUMOZ). However adult survival in both cases was relatively high (32 median days for FUTAZ and 52 days for FUMOZ); with both strains living well beyond the minimum period required to produce eggs and transmit malaria. Another laboratory study conducted on FUMOZ where adult life span ranged from 39 to 64 days [65]; again much higher than $F_{1}$-FUTAZ here. The shorter life span of FUTAZ relative to FUMOZ may be a result of the stress from the change of environment, or lack of adaption to laboratory conditions. Nevertheless, this $F_{1}$-FUTAZ survived much longer compared to another competent vectors 
of malaria transmission, Anopheles arabiensis and An. gambiae s.s. in the laboratory conditions [21]. Previous experiments on parity shows that the median survival of An. funestus in the wild is much shorter, ranging from 7 to 10 days in the wild population [85]. Thus, poor adult survival relative to the wild cannot explain the failure of colonization here.

A potential limitation of our study is that the unfed An. funestus females were used to seed laboratory colonies, requiring us to blood feed them artificially (on chicken blood) in the laboratory to acquire eggs for the next generation. Thus, the mating status and age of the wild females used for colonization were uncertain and likely variable. An alternative would have been to collect only visibly blood fed females during field collections (these individuals would likely had fed on humans if caught inside houses), and used their eggs to generate the $\mathrm{F}_{1}$ generation. This was considered, but given the much lower abundance of blood fed An. funestus inside houses compared to the numbers of unfed females that can be obtained in CDC light traps; the latter approach was chosen to ensure sufficiently large samples were obtained for colonization experiments. These wild mosquitoes could not be provided with a human blood meal given their malaria infection status was unknown and they were not adapted to membrane feeding, thus chicken blood was provided. This variation in host blood source could have generated some differences in fitness between strains. However, this is unlikely given that previous studies indicate that human and chicken blood meals generate similar egg production in other African malaria vector species under laboratory conditions (An. arabiensis and An. gambiae $[21,86])$. The $\mathrm{F}_{1}$ population, upon which the main fitness indicators were assessed, was fed on human blood. Further investigation is required to confirm whether An. funestus fitness is impacted by the type of host blood meals provided and whether there is an optimal diet for laboratory maintenance.

\section{Conclusions}

Laboratory colonies remain fundamental for research on the biology and control of mosquito vectors, by providing a stable and standardized source of mosquitoes for experimental studies. This study provides additional evidence of the intractability of An. funestus to colonization. By quantifying a comprehensive range of fitness traits during unsuccessful attempts, this study generates insights into the most important barriers to colonization. Of the range of traits investigated, the primary barrier to colonization was identified as low mating success, compounded further by the slow development and poor survival of the small numbers of larvae produced. Additionally, both the fecundity and adult survival of An. funestus offspring from wild parents were reduced under laboratory conditions, but these impacts may have been relatively minor compared to the consequences of poor mating success and poor larval survival. This combination of fitness deficits presents a major challenge for successful colonization and mass rearing of An. funestus. To overcome this, future research should focus on enhancing the efficiency these life-cycle processes under insectary conditions. Additionally, the demographic rates estimated from wild and $F_{1}$-FUTAZ will provide useful baseline information for understanding and modeling An. funestus population dynamics in general, and guiding further attempts to its colonization.

\section{Supplementary Information}

The online version contains supplementary material available at https://doi. org/10.1186/s12936-021-03677-3.

Additional file 1: Table S1. Descriptions of terms used and strains compared as used in this study. Table S2. Total number of mosquitoes for each replicates and sex as used during the survival analysis between two strains (of FUTAZ and FUMOZ). Figure S1. Images of: a) Series of wooden cages with oviposition cups, each containing a single fully-engorged Anopheles funestus female. Individual cups were used to measure the number of eggs laid by a single mosquito after full blood meal, b) Technician counting the number of eggs and measuring the wing sizes of individual mosquitoes which have laid eggs, c) Technician aspirating mosquitoes from the rearing cage using mouth aspirator and $\mathbf{d}$ ) bowl contains eggs of Anopheles funestus. All experiment was done within the VectorSphere at Ifakara Health Institute.

\section{Acknowledgments}

We are grateful to IHI-VectorSphere insectary's technician Joseph Mgando, Dickson Mwasheshi, Godfrey Matanila and Neema Nombo for their contributions in different occasion during mosquito rearing and colonization. We are also acknowledging the contributions of Rukiyah Mohammed, Issa Mshani, Khamis Bwanaally and Jamie Sebastian during data collection both in the field and insectary. We are also grateful for the two anonymous reviewers for providing constructive comments.

\section{Authors' contributions}

$\mathrm{HSN}, \mathrm{FOO}$ and HMF designed the study. HSN and EEH conducted the experiment and data collection. HSN conducted the formal data analysis. HSN drafted the manuscript. FOO, HMF and JM reviewed the manuscript and provide supervision. All authors read and approved the final manuscript.

\section{Funding}

This work was supported by Howard Hughes Medical Institute (HHMI) and Gates Foundation (Grants: OPP1099295) awarded to FOO and HMF. HSN and EEH are supported by HHMI Grant (OPP1099295) awarded to FOO.

\section{Availability of data and materials}

The dataset generated by this study is available from the corresponding author upon reasonable request.

\section{Declarations}

\section{Ethics approval and consent to participate}

This study was approved by Ifakara Health Institute Institutional Review Board (Ref. IHI/IRB/No: 007-2018) and the Medical Research Coordinating Committee (MRCC) at the National Institute for Medical Research-NIMR (Ref: NIMR/ HQ/R.8a/Nol.IX/2895). Individual verbal and written consent was also obtained from household owners where CDC light traps were placed for collecting mosquitoes and verbal consent for the arm-feeders in the insectary. 


\section{Consent for publication}

Permission to publish was obtained from Medical Research Coordinating Committee (MRCC) at the National Institute for Medical Research (Ref: NIMR/ HQ/P.12 VOL XXXI/57).

\section{Competing interests}

The authors declare no conflicts of interest.

\begin{abstract}
Author details
${ }^{1}$ Department of Environmental Health and Ecological Sciences, Ifakara Health Institute, P.O. Box 53, Ifakara, Tanzania. ${ }^{2}$ Institute of Biodiversity, Animal Health and Comparative Medicine, University of Glasgow, Glasgow G12,8QQ, UK. ${ }^{3}$ School of Public Health, University of the Witwatersrand, 1 Smuts Avenue, Braamfontein 2000, Republic of South Africa. ${ }^{4}$ School of Life Science and Bioengineering, Nelson Mandela African Institution of Science and Technology, P.O. Box 447, Arusha, Tanzania.
\end{abstract}

Received: 5 November 2020 Accepted: 1 March 2021 Published online: 12 March 2021

\section{References}

1. Bhatt S, Weiss DJ, Cameron E, Bisanzio D, Mappin B, Dalrymple U, et al. The effect of malaria control on Plasmodium falciparum in Africa between 2000 and 2015. Nature. 2015;526:207-11.

2. TMIS. Tanzania Malaria Indicator Survey Key indicators 2017. Decis. Support Syst. 2017.

3. Ferguson HM, Ng'habi KR, Walder T, Kadungula D, Moore SJ, Lyimo I, et al. Establishment of a large semi-field system for experimental study of African malaria vector ecology and control in Tanzania. Malar J. 2008;7:158.

4. Ng'habi KR, Lee Y, Knols BGJ, Mwasheshi D, Lanzaro GC, Ferguson HM. Colonization of malaria vectors under semi-field conditions as a strategy for maintaining genetic and phenotypic similarity with wild populations. Malar J. 2015:14:10.

5. Okumu FO, Kotas ME, Kihonda J, Mathenge E, Killeen GF, Moore SJ. Comparative evaluation of methods used for sampling malaria vectors in the Kilombero Valley, South Eastern Tanzania. Open Trop Med J. 2008;1:51-5.

6. Ngowo HS, Kaindoa EW, Matthiopoulos J, Ferguson HM, Okumu FO. Variations in household microclimate affect outdoor-biting behaviour of malaria vectors. Wellcome Open Res. 2017;2:102.

7. Depinay JMO, Mbogo CM, Killeen G, Knols B, Beier J, Carlson J, et al. A simulation model of African Anopheles ecology and population dynamics for the analysis of malaria transmission. Malar J. 2004;3:29.

8. Minakawa N, Githure JI, Beier JC, Yan G. Anopheline mosquito survival strategies during the dry period in western Kenya. J Med Entomol. 2001;38:388-92.

9. Fillinger U, Sonye G, Killeen GF, Knols BGJ, Becker N. The practical importance of permanent and semipermanent habitats for controlling aquatic stages of Anopheles gambiae sensu lato mosquitoes: operational observations from a rural town in western Kenya. Trop Med Int Health. 2004;9:1274-89.

10. Matowo NS, Munhenga G, Tanner M, Coetzee M, Feringa WF, Ngowo $\mathrm{HS}$, et al. Fine-scale spatial and temporal heterogeneities in insecticide resistance profiles of the malaria vector, Anopheles arabiensis in rural south-eastern Tanzania. Wellcome Open Res. 2017;2:96.

11. Ranson H, Abdallah H, Badolo A, Guelbeogo W, Kerah-Hinzoumbé C, Yangalbé-Kalnoné E, et al. Insecticide resistance in Anopheles gambiae: data from the first year of a multi-country study highlight the extent of the problem. Malar J. 2009;8:299.

12. Williams J, Flood L, Praulins G, Ingham VA, Morgan J, Lees RS, et al. Characterisation of Anopheles strains used for laboratory screening of new vector control products. Parasit Vectors. 2019;12:522.

13. Tripet F, Touré $Y T$, Taylor CE, Norris DE, Dolo G, Lanzaro GC. DNA analysis of transferred sperm reveals significant levels of gene flow between molecular forms of Anopheles gambiae. Mol Ecol. 2001;10:1725-32.

14. Kyrou K, Hammond AM, Galizi R, Kranjc N, Burt A, Beaghton AK, et al. A CRISPR-Cas9 gene drive targeting doublesex causes complete population suppression in caged Anopheles gambiae mosquitoes. Nat Biotechnol. 2018:36:1062-71.
15. Christophides GK, Zdobnov E, Barillas-Mury C, Birney E, Blandin S, Blass C, et al. Immunity-related genes and gene families in Anopheles gambiae. Science. 2002;298:159-65.

16. Waterhouse RM, Kriventseva EV, Meister S, Xi Z, Alvarez KS, Bartholomay LC, et al. Evolutionary dynamics of immune-related genes and pathways in disease-vector mosquitoes. Science. 2007;316:1738-43.

17. Russell TL, Lwetoijera DW, Knols BGJ, Takken W, Killeen GF, Ferguson HM. Linking individual phenotype to density-dependent population growth: the influence of body size on the population dynamics of malaria vectors. Proc Biol Sci. 2011;278:3142-51.

18. Seyoum A, Sikaala CH, Chanda J, Chinula D, Ntamatungiro AJ, Hawela $M$, et al. Human exposure to anopheline mosquitoes occurs primarily indoors, even for users of insecticide-treated nets in Luangwa Valley, South-east Zambia. Parasit Vectors. 2012;5:101.

19. Maia MF, Kreppel K, Mbeyela E, Roman D, Mayagaya V, Lobo NF, et al. A crossover study to evaluate the diversion of malaria vectors in a community with incomplete coverage of spatial repellents in the Kilombero Valley, Tanzania. Parasit Vectors. 2016;9:451.

20. Viana M, Ng'habi K, Lyimo I, Ferguson HM, Matthiopoulos J, Killeen G. Mesocosm experiments reveal the impact of mosquito control measures on malaria vector life history and population dynamics. Sci Rep. 2018;8:13949.

21. Lyimo IN, Haydon DT, Russell TL, Mbina KF, Daraja AA, Mbehela EM, et al. The impact of host species and vector control measures on the fitness of African malaria vectors. Proc Biol Sci. 2013;280:20122823.

22. Gillies M, Meillon D. The Anophelinae of Africa south of the Sahara (Ethiopian zoogeographical region). Publ S Afr Inst Med Res. 1968; pp. 343.

23. Vezenegho SB, Chiphwanya J, Hunt RH, Coetzee M, Bass C, Koekemoer LL. Characterization of the Anopheles funestus group, including Anopheles funestus-like, from Northern Malawi. Trans R Soc Trop Med Hyg. 2013;107:753-62

24. Mouatcho J, Cornel AJ, Dahan-Moss Y, Koekemoer LL, Coetzee M, Braack L. Detection of Anopheles rivulorum-like, a member of the Anopheles funestus group, in South Africa. Malar J. 2018;17:95.

25. Dia I, Guelbeogo MW, Ayala D. Advances and perspectives in the study of the malaria mosquito Anopheles funestus. In: Manguin S, editor. Anopheles mosquitoes - new insights into malaria vectors. Rijeka: InTech Open; 2013.

26. Coetzee M, Fontenille D. Advances in the study of Anopheles funestus, a major vector of malaria in Africa. Insect Biochem Mol Biol. 2004;34:599-605.

27. Kaindoa EW, Matowo NS, Ngowo HS, Mkandawile G, Mmbando A, Finda $M$, et al. Interventions that effectively target Anopheles funestus mosquitoes could significantly improve control of persistent malaria transmission in south-eastern Tanzania. PLoS ONE. 2017;12:e0177807.

28. Lwetoijera D, Harris C, Kiware SS, Dongus S, Devine GJ, McCall PJ, et al. Increasing role of Anopheles funestus and Anopheles arabiensis in malaria transmission in the Kilombero Valley, Tanzania. Malar J. 2014;13:331.

29. Kawada H, Dida GO, Sonye G, Njenga SM, Mwandawiro C, Minakawa N. Reconsideration of Anopheles rivulorum as a vector of Plasmodium falciparum in western Kenya: some evidence from biting time, blood preference, sporozoite positive rate, and pyrethroid resistance. Parasit Vectors. 2012;5:230

30. Wilkes TJ, Matola YG, Charlwood JD. Anopheles rivulorum, a vector of human malaria in Africa. Med Vet Entomol. 1996;10:108-10.

31. Burke A, Dandalo L, Munhenga G, Dahan-Moss Y, Mbokazi F, Ngxongo $\mathrm{S}$, et al. A new malaria vector mosquito in South Africa. Sci Rep. 2017:7:43779.

32. Hunt RH, Brooke BD, Pillay C, Koekemoer LL, Coetzee M. Laboratory selection for and characteristics of pyrethroid resistance in the malaria vector Anopheles funestus. Med Vet Entomol. 2005;19:271-5.

33. Hargreaves K, Koekemoer LL, Brooke BD, Hunt RH, Mthembu J, Coetzee M. Anopheles funestus resistant to pyrethroid insecticides in South Africa. Med Vet Entomol. 2000;14:181-9.

34. Service MW, Oguamah D. Colonization of Anopheles funestus. Nature. 1958;181:1225

35. Nepomichene TN, Andrianaivolambo L, Boyer S, Bourgouin C. Efficient method for establishing F1 progeny from wild populations of Anopheles mosquitoes. Malar J. 2017;16:21.

36. Wijit A, Taai K, Dedkhad W, Hempolchom C, Thongsahuan S, Srisuka W, et al. Comparative studies on the Stenogamous and Eurygamous 
behavior of eight Anopheles species of the Hyrcanus Group (Diptera: Culicidae) in Thailand. Insects. 2016;7:11.

37. Kim S, Trocke S, Sim C. Comparative studies of stenogamous behaviour in the mosquito Culex pipiens complex. Med Vet Entomol. 2018;32:427-35.

38. Lardeux F, Quispe V, Tejerina R, Rodríguez R. Laboratory colonization of Anopheles pseudopunctipennis (Diptera: Culicidae) without forced mating. C R Biol. 2007;330:571-5.

39. Sallum MAM, Peyton EL, Wilkerson RC. Six new species of the Anopheles leucosphyrus group, reinterpretation of An. elegans and vector implications. Med Vet Entomol. 2005;19:158-99.

40. Phasomkusolsil S, Wongnet O, Pantuwatana K, Tawong J, Monkanna $\mathrm{N}$, Kornkan T, et al. Comparison of Anopheles cracens (Stenogamous) and Anopheles dirus (Eurygamous) blood-feeding behaviors, survival rates and fecundity after first and second blood meals. Int J Mosq Res. 2019;6:14-21.

41. Kaindoa EW, Ngowo HS, Limwagu A, Mkandawile G, Kihonda J, Masalu JP, et al. New evidence of mating swarms of the malaria vector, Anopheles arabiensis in Tanzania. Wellcome Open Res. 2017;2:88.

42. Kaindoa EW, Ngowo HS, Limwagu AJ, Tchouakui M, Hape E, Abbasi S, et al. Swarms of the malaria vector Anopheles funestus in Tanzania. Malar J. 2019;18:29.

43. Sawadogo PS, Namountougou M, Toé KH, Rouamba J, Maïga H, Ouédraogo KR, et al. Swarming behaviour in natural populations of Anopheles gambiae and An. coluzzii: review of 4 years survey in rural areas of sympatry, Burkina Faso (West Africa). Acta Trop. 2014;130:24-34.

44. Dao A, Adamou A, Yaro AS, Maïga M, Kassogue Y, Traoré SF, et al. Assessment of alternative mating strategies in Anopheles gambiae: does mating occur indoors? J Med Entomol. 2008;45:643-52.

45. Killeen GF. Characterizing, controlling and eliminating residual malaria transmission. Malar J. 2014;13:330.

46. Moiroux N, Gomez MB, Pennetier C, Elanga E, Djènontin A, Chandre F, et al. Changes in Anopheles funestus biting behavior following universal coverage of long-lasting insecticidal nets in benin. J Infect Dis. 2012;206:1622-9.

47. Msugupakulya BJ, Kaindoa EW, Ngowo HS, Kihonda JM, Kahamba NF, Msaky DS, et al. Preferred resting surfaces of dominant malaria vectors inside different house types in rural south-eastern Tanzania. Malar J. 2020;19:22.

48. Sudia WD, Chamberlain RW. Battery-operated light trap, an improved model. J Am Mosq Control Assoc. 1988;4:536-8.

49. Odetoyinbo JA. Preliminary investigation on the use of a light-trap for sampling malaria vectors in the Gambia. Bull World Health Organ. 1969;40:547-60.

50. Gillies M, Coetzee M. A supplement to the anophelinae of Africa South of the Sahara. Publ South African Inst Med Res. 1987;55:63.

51. Koekemoer LL, Kamau L, Hunt RH, Coetzee M. A cocktail polymerase chain reaction assay to identify members of the Anopheles funestus (Diptera: Culicidae) group. Am JTrop Med Hyg. 2002;66:804-11.

52. Moorefield HH. Sexual dimorphism in mosquito pupae. Mosq News. 1951;11:175-7.

53. Carvalho DO, Nimmo D, Naish N, McKemey AR, Gray P, Wilke ABB, et al. Mass production of genetically modified Aedes aegypti for field releases in Brazil. J Vis Exp. 2014;83:e3579.

54. Gillies MT. The duration of the gonotrophic cycle in Anopheles gambiae and Anopheles funestus, with a note on the efficiency of hand catching. East Afr Med J. 1953;30:129-35.

55. Olayemi IK, Ande AT. Life table analysis of Anopheles gambiae (Diptera: Culicidae) in relation to malaria transmission. J Vector Borne Dis. 2009:46:295-8.

56. Nasci RS. Relationship of wing length to adult dry weight in several mosquito species (Diptera: Culicidae). J Med Entomol. 1990;27:716-9.

57. R Development Core Team. R: A language and environment for statistical computing. R Foundation Stat Comput. 2018.

58. Bates D, Maechler M, Bolker B, Walker S. Ime4: linear mixed-effects models using S4 classes. R package version 1.1-6. R. 2014.

59. Lumley T, S- R, Elizabeth A, Cynthia C. Package' survival 'for Survival Analysis. 2020.

60. Hougaard P. Frailty models for survival data. Lifetime Data Anal. 1995;1:255-73.

61. Balan TA, Putter H. A tutorial on frailty models. Stat. Methods Med. Res. SAGE Publications Ltd; 2020. p. 3424-54.
62. Wickham H. R Graphics Cookbook. Media. 2009;35:211.

63. Kassambara A, Kosinski M, Biecek P. Package survminer Type Package Title Drawing Survival Curves using "ggplot2." MranMicrosoftCom. 2017.

64. Tchigossou GM, Akoton R, Yessoufou A, Djegbe I, Zeukeng F, Atoyebi SM, et al. Water source most suitable for rearing a sensitive malaria vector, Anopheles funestus in the laboratory. Wellcome Open Res. 2018;2:109.

65. Okoye PN, Brooke BD, Hunt RH, Coetzee M. Relative developmental and reproductive fitness associated with pyrethroid resistance in the major southern African malaria vector, Anopheles funestus. Bull Entomol Res. 2007:97:599-605.

66. Thailayil J, Magnusson K, Godfray HCJ, Crisanti A, Catteruccia F. Spermless males elicit large-scale female responses to mating in the malaria mosquito Anopheles gambiae. Proc Natl Acad Sci USA. 2011;108:13677-81.

67. Impoinvil DE, Cardenas GA, Gihture Jl, Mbogo CM, Beier JC. Constant temperature and time period effects on Anopheles gambiae egg hatching. J Am Mosq Control Assoc. 2007;23:124-30.

68. Tchouakui M, Riveron JM, Djonabaye D, Tchapga W, Irving H, Takam PS, et al. Fitness costs of the glutathione S-transferase epsilon 2 (L119FGSTe2) mediated metabolic resistance to insecticides in the major African malaria vector Anopheles funestus. Genes (Basel). 2018;9:645.

69. Schneider P, Takken W, McCall PJ. Interspecific competition between sibling species larvae of Anopheles arabiensis and An. gambiae. Med Vet Entomol. 2000;14:165-70.

70. Awono-Ambéné HP, Robert V. survival and emergence of immature Anopheles arabiensis mosquitoes in market-gardener wells in Dakar. Senegal Parasite. 1999;6:179-84.

71. Paaijmans KP, Huijben S, Githeko AK, Takken W. Competitive interactions between larvae of the malaria mosquitoes Anopheles arabiensis and Anopheles gambiae under semi-field conditions in western Kenya. Acta Trop. 2009;109:124-30.

72. Service MW. Mortalities of the immature stages of species $b$ of the Anopheles gambiae complex in Kenya: comparison between rice fields and temporary pools, identification of predators, and effects of insecticidal spraying. J Med Entomol. 1977;13:535-45.

73. Ng'habi KRN, Mwasheshi D, Knols BGJ, Ferguson HM. Establishment of a self-propagating population of the African malaria vector Anopheles arabiensis under semi-field conditions. Malar J. 2010;9:356.

74. Clements AN. The biology of mosquitoes. Wallingford: Cabi International; 2011.

75. Ng'habi KRN, John B, Nkwengulila G, Knols BGJ, Killeen GF, Ferguson HM. Effect of larval crowding on mating competitiveness of Anopheles gambiae mosquitoes. Malar J. 2005;4:49.

76. Takken W, Klowden MJ, Chambers GM. Effect of body size on host seeking and blood meal utilization in Anopheles gambiae sensu stricto (Diptera: Culicidae): the disadvantage of being small. J Med Entomol. 1998;35:639-45.

77. Huho BJ, Nghabi KR, Killeen GF, Nkwengulila G, Knols BGJ, Ferguson HM. Nature beats nurture: a case study of the physiological fitness of free-living and laboratory-reared male Anopheles gambiae s.l. J Exp Biol. 2007;210:2939-47.

78. Charlwood JD, Thompson R, Madsen H. Observations on the swarming and mating behaviour of Anopheles funestus from southern Mozambique. Malar J. 2003;2:2.

79. Charlwood JD. Studies on the bionomics of male Anopheles gambiae Giles and male Anopheles funestus Giles from southern Mozambique. J Vector Ecol. 2011;36:382-94.

80. Ferguson HM, John B, Ng'habi K, Knols BGJ. Redressing the sex imbalance in knowledge of vector biology. Trends Ecol Evol. 2005;20:202-9.

81. Baker RH. Mating problems as related to the establishment and maintenance of laboratory colonies of mosquitos. Bull World Health Organ. 1964;31:467-8.

82. Bryan JH, Southgate BA. Studies of forced mating techniques on anopheline mosquitoes. Mosq News. 1978;38:338-42.

83. Villarreal C, Arredondo-Jimenez J, Rodrigueze MH, Ulloa A. Colonization of Anopheles pseudopunctipennis from Mexico. J Am Mosq Assoc. 1998;14:369-72.

84. Baerg DC. Colonization of Anopheles pseudopunctipennis in Panama. J Med Entomol. 1971;8:180-2. 
85. Gillies MT, Wilkes TJ. A study of the age-composition of populations of Anopheles gambiae Giles and Afunestus Giles in North-Eastern Tanzania. Bull Entomol Res. 1965;56:237-62.

86. Lyimo IN, Haydon DT, Mbina KF, Daraja AA, Mbehela EM, Reeve R, et al. The fitness of African malaria vectors in the presence and limitation of host behaviour. Malar J. 2012;11:425.

\section{Publisher's Note}

Springer Nature remains neutral with regard to jurisdictional claims in published maps and institutional affiliations.
Ready to submit your research? Choose BMC and benefit from:

- fast, convenient online submission

- thorough peer review by experienced researchers in your field

- rapid publication on acceptance

- support for research data, including large and complex data types

- gold Open Access which fosters wider collaboration and increased citations

- maximum visibility for your research: over 100M website views per year

At BMC, research is always in progress.

Learn more biomedcentral.com/submissions 